\title{
New pharmaceutical applications for macromolecular binders
}

\author{
Nicolas Bertrand ${ }^{\mathrm{a}}$, Marc A. Gauthier ${ }^{\mathrm{b}}$, Céline Bouvet ${ }^{\mathrm{a}}$, Pierre Moreau ${ }^{\mathrm{a}}$, Anne Petitjean ${ }^{\mathrm{c}}$, \\ Jean-Christophe Leroux ${ }^{\mathrm{a}, \mathrm{b}, *}$, Jeanne Leblond ${ }^{\mathrm{a}, * *}$ \\ a Faculty of Pharmacy, Université de Montréal, P.O. Box 6128, Downtown Station, Montréal, Québec, H3C 3J7, Canada \\ ${ }^{\mathrm{b}}$ Department of Chemistry and Applied Biosciences, Institute of Pharmaceutical Sciences, ETH Zürich, Wolfgang-Pauli Str. 10, 8093 Zürich, Switzerland \\ c Department of Chemistry, Queen's University, 90 Bader Lane, Kingston, Ontario, K7L 3N6, Canada
}

\section{A R T I C L E I N F O}

Article history:

Received 16 February 2011

Accepted 27 April 2011

Available online 5 May 2011

\section{Keywords:}

Polymeric drugs

Polymeric binders

Chelators

Cyclodextrins

Nanomedicine

\begin{abstract}
A B S T R A C T
Macromolecular binders consist of polymers, dendrimers, and oligomers with binding properties for endogenous or exogenous substrates. This field, at the frontier of host/guest chemistry and pharmacology, has met a renewed interest in the past decade due to the clinical success of several sequestrants, like sevelamer hydrochloride (Renagel ${ }^{\circledR}$ ) or sugammadex (Bridion ${ }^{\circledR}$ ). In many instances, multivalent binding by the macromolecular drugs can modify the properties of the substrate, and may prevent it from reaching its site of action and/or trigger a biological response. From small (e.g., ions) to larger substrates (e.g., bacteria and cells), this review presents the state-of-the-art of macromolecular binders and provides detailed illustrative examples of recent developments bearing much promise for future pharmaceutical applications.
\end{abstract}

(C) 2011 Elsevier B.V. All rights reserved.

\section{Introduction}

Since the beginning of pharmaceutical technology, polymers and macromolecules have evolved from inert pharmaceutical ingredients to central components in most contemporary biomedical applications [1-4]. The macromolecules are generally used to alter the physicochemical properties or biopharmaceutical characteristics of an active compound (enhanced circulation time, resistance to enzymatic degradation, etc.). This approach distinguishes itself from systems in which the macromolecule presents an intrinsic pharmacological activity per se [5]. Most current and prospective applications of bioactive macromolecules exploit their ability to avidly bind different types of compounds. For polymers, these properties stem from their flexible and modular structure, the repeating nature of recognition moieties, and their compatibility with a broad range of recognition moieties. The high valency provided by each chemical unit favors improved binding over comparable monovalent systems [6,7]. Other macromolecular systems such as cyclodextrins (CD) utilize their intrinsic three-dimensional structure and relative disposition of functional groups rather than pendant recognition moieties to bind substrates $[8,9]$.

* Correspondence to: J.-C. Leroux, Department of Chemistry and Applied Biosciences, Institute of Pharmaceutical Sciences, ETH Zürich, Wolfgang-Pauli Str. 10, 8093 Zürich, Switzerland. Tel./fax: +41446331311.

** Corresponding author. Faculty of Pharmacy, Université de Montréal, P.O. Box 6128, Downtown Station, Montréal, Québec, H3C 3J7, Canada. Tel.: +1 514343 6455; fax: + 15143436871

E-mail addresses: nicolas.bertrand@umontreal.ca (N. Bertrand), marc.gauthier@pharma.ethz.ch (M.A. Gauthier),celine.bouvet@umontreal.ca (C. Bouvet), pierre.moreau@umontreal.ca (P. Moreau), petitjea@chem.queensu.ca (A. Petitjean), jleroux@ethz.ch (J.-C. Leroux), jeanne.chain@umontreal.ca (J. Leblond).
The mechanism by which polymeric binders exert a therapeutic effect varies depending on the size of the substrate. For instance, the binding of a small-molecule or ionic substrate changes considerably its hydrodynamic size. This translates into restricted permeability through biological barriers and decreased diffusional and rotational freedom to reach sites of action. For larger substrates, the polymeric binder alters surface properties to trigger or suppress biological responses. Interestingly, in certain cases, the architecture of the binding moieties can lead to a spatial re-organization of the substrates, which in turn provokes a desired cellular signalization [10,11]. Hence, depending on the application sought after, chemical and structural parameters can be tuned in the design of macromolecular binders [5,12].

Historically, the first commercialized polymeric binders have exploited the abovementioned characteristics to lower the blood levels of various ions such as potassium and phosphate, as well as small molecules such as cholesterol [12]. With advances in polymer chemistry [13], the availability of more synthetically sophisticated macromolecules has ensued and opened the possibility of specifically binding more complex substrates such as peptides and proteins. These biological substrates can be present in solution or on the surface of viruses, bacteria and cells.

This manuscript surveys recent aspects of the use of (semi) synthetic macromolecular binders for therapeutic applications. The scope of macromolecular binders reviewed herein includes synthetic polymers, dendrimers, and oligomers which exhibit binding properties towards endogenous or exogenous substrates and does not discuss natural biomacromolecular binders such as e.g., antibodies. Molecularly imprinted polymers will not be examined either, and the reader is referred to excellent reviews for more information on this topic $[14,15]$. This article has no intention of being a comprehensive 
review but is rather geared to highlight both the state-of-the-art of macromolecular binders as well as recent innovative and/or important examples which illustrate current progress in the field (Table 1). It is divided into 6 sections, consecutively discussing the binding of ions $\left(10^{-10} \mathrm{~m}\right)$, small-molecules, peptides and short-strand nucleic acids $\left(10^{-9} \mathrm{~m}\right)$, proteins $\left(10^{-9}-10^{-8} \mathrm{~m}\right)$, viruses $\left(10^{-8}-10^{-7} \mathrm{~m}\right)$, bacteria $\left(10^{-6} \mathrm{~m}\right)$, and cells $\left(10^{-5} \mathrm{~m}\right)$.

\section{Macromolecular binders for ions}

The sequestration of ions can be achieved in several manners through interactions such as coordination bonds, ion-ion interactions, hydrogen bonding, and ion-aromatic interactions (ranked from strongest to weakest) [42]. Even though high selectivity towards such a trivial substrate is difficult to achieve, incorporation of one or several of the interactions above into a macromolecular sequestrant can lead to exceptionally high binding affinity. Moreover, with the considerably different physical properties of macromolecules and ions, interactions between both species can dramatically modify the biological activity of electrolytes and thus a therapeutic response can be harnessed.

\subsection{State-of-the-art}

Electrolyte concentration, a paramount component of whole-body homeostasis, is regulated by the complex elimination and re-absorption functions of the kidneys. Renal failure, including chronic kidney disease and end-stage renal disease, can result in ion overload. Among other electrolytic disorders, hyperphosphatemia represents a major risk for morbidity and mortality in patients undergoing dialysis because of complications such as soft tissue calcification, renal bone disease, and secondary hyperparathyroidism [12]. Until recently, treatment of hyperphosphatemia consisted in aluminum- and calcium-based sequestrants which unfortunately have been shown to induce neurologic toxicity or calcium overload and soft tissue calcification [43]. A major improvement has been achieved with the clinical development of sevelamer hydrochloride (Renagel $\left.{ }^{\circledR}\right)$, a copolymer of allylamine crosslinked with epichlorohydrin. The cationic amine-based polymer is able to sequester dietary phosphate in the gastrointestinal (GI) tract and excrete the complex in the feces [17]. In addition to the decrease of serum phosphate levels, sevelamer hydrochloride has demonstrated the ability to reduce the risk of calcification. Its efficiency relies on the stable ionic interactions between the abundant phosphate anion (average daily dietary intake ranges from 1 to $1.8 \mathrm{~g}$ [43]) and the cationic polymer. Cross-linking of the polymer was achieved to maximize binding in the GI tract through a multivalent chelating effect [44]. This strategy was inspired by Kayexalate ${ }^{\circledR}$, a commercialized polymeric sequestrant for the treatment of hyperkalemia [16]. The binder is a sodium polystyrene sulfonate resin which exchanges sodium against potassium in the GI tract. More recently, a similar approach was proposed for iron. Thus far, iron overload has been treated with frequent parenteral infusions of low molecular weight desferrioxamine, a chelator of ferric ions [12]. Alternative strategies have examined polymeric sequestrants, either to improve desferrioxamine blood circulation times by grafting to a polymeric [18] and dendrimeric [19] backbone or to develop molecules with stronger coordination interactions [20]. For example, Zhou et al. [20] have proposed a hexadentate ligand-bearing polymeric chelator which presents an ideal geometry to provide octahedral coordination sites for

Table 1

Examples of macromolecular binders on the market or under investigation as of March 2011

\begin{tabular}{|c|c|c|c|c|c|c|}
\hline & Binder name & Material & Administration route & Substrate & Status & Reference \\
\hline \multirow[t]{6}{*}{ Ions } & Kayexalate & Polystyrene sulfonate & Oral & Potassium & Approved & [16] \\
\hline & Sevelamer & Crosslinked allylamine & Oral & Phosphate & Approved & [17] \\
\hline & - & PEG-desferrioxamine & Parenteral & Iron & Discovery & [18] \\
\hline & - & Dendrimer-desferrioxamine & Parenteral & Iron & Discovery & [19] \\
\hline & - & PAA-hexadentate ligand & Parenteral & Iron & Discovery & [20] \\
\hline & - & PEG-CAF & Parenteral & Heavy metals & Discovery & \\
\hline \multirow[t]{5}{*}{ Small molecules } & Cholestyramine & poly(divinylbenzene-co (vinylbenzyl)trimethylammonium) & Oral & Bile salts & Approved & \\
\hline & - & $\beta C D$ derivative & Parenteral & Cholesterol & Approved & {$[21]$} \\
\hline & Sugammadex & $\gamma \mathrm{CD}$ derivative & Parenteral & Rocuronium & Approved & {$[22]$} \\
\hline & - & $\beta C D$-containing polycation & Parenteral & Aptamers & Discovery & [23] \\
\hline & - & Oligochitosan derivative & Parenteral & Amitriptyline & Discovery & [24] \\
\hline \multirow[t]{10}{*}{ Peptides and proteins } & Synsorb 90 & Chromosorb P-trisaccharide & Oral & C. difficile toxins & Phase II $^{\mathrm{a}}$ & {$[25]$} \\
\hline & Tolevamer & PSS & Oral & C. difficile toxins & Phase III ${ }^{\mathrm{a}}$ & [25] \\
\hline & - & P(HEMA-co-SS) & Oral & Gluten & Discovery & [26] \\
\hline & Starfish & Carbohydrate & Parenteral & Shiga toxins & Discovery & [27] \\
\hline & - & PAA-carbohydrate & Oral & Shiga toxins & Discovery & [28] \\
\hline & (S)-PolyBAIT & PAA-carbohydrate + templating protein & Parenteral & Shiga toxins & Discovery & [29] \\
\hline & - & PAA-peptide & Parenteral & Anthrax toxins & Discovery & [30] \\
\hline & - & PAA-peptide & Parenteral & Anthrax toxins & Discovery & [31] \\
\hline & - & PGA-peptide & Parenteral & Anthrax toxins & Discovery & [32] \\
\hline & - & PDMDOMA & In vitro & Fibrin & Discovery & [33] \\
\hline \multirow[t]{3}{*}{ Viruses } & - & Poly(lysine) dendrimer & Mucosal & HIV-1 and HSV-2 & Phase I/II & [34] \\
\hline & - & PGA-sialidase inhibitor & Parenteral & Influenza & Discovery & [35] \\
\hline & - & PAA-trisaccharide & Parenteral & Influenza & Discovery & [36] \\
\hline \multirow[t]{3}{*}{ Bacterias } & - & Poly(lysine) dendrimer & Mucosal & Bacterial vaginosis & Phase II & [37] \\
\hline & - & $\mathrm{p}(\mathrm{A}-\mathrm{V}-\mathrm{F})$ & In vitro & Gram-positive bacteria & Discovery & [38] \\
\hline & - & PAA-carbohydrate & In vitro & E. Coli & Discovery & [39] \\
\hline \multirow[t]{2}{*}{ Cells } & - & dPGS & Parenteral & L- and P-selectins & Discovery & {$[40]$} \\
\hline & - & PHPMA-peptide & In vitro & $\mathrm{CD} 20$ & Discovery & [41] \\
\hline
\end{tabular}

PAA: poly(acrylamide).

$\mathrm{P}($ HEMA-co-SS): poly(Hydroxyethylmetacrylate)-co-(styrene sulfonate).

PSS: poly(styrene sulfonate).

dPGS: dendritic polyglycerol sulfate.

$\mathrm{p}(\mathrm{A}-\mathrm{V}-\mathrm{F})$ : vancomycin/fluorescein functionalized polyacrylamide polymer.

PHPMA: poly(N-(2-hydroxypropyl)-methacrylamide).

PGA: poly(L-glutamic acid).

PDMDOMA: Poly- $N$-[(2,2-dimethyl-1,3-dioxolane)methyl]acrylamide.

a Terminated. 
iron chelation and thus forms stable iron complexes. Although in vitro results were promising in both strategies above, no in vivo experiments have been reported to date.

\subsection{Selected recent example: poly(ethylene glycol)-caffeine conjugate (PEG-CAF)}

Although present in much lower concentrations than physiological electrolytes like potassium and phosphate, heavy metals can cause severe adverse health effects. Arsenic, mercury, lead, and cadmium all rank in the top 10 on the current Agency for Toxic Substances and Disease Registry's priority list of hazardous substances [45]. Because they are poorly eliminated, they have a very long biological half-life and can accumulate in the organism throughout a person's entire life. Their toxicity after either acute or chronic exposure can occur at very low doses and generally involves numerous organs [46,47]. Like iron overload, most efficient detoxification therapies have focused on chelating agents [48]. Among the numerous agents examined, low molecular weight compounds British anti Lewisite (BAL) and calcium disodium ethylenediaminetetraacetic acid (EDTA) have been used since the 1950s. However, these agents induce multiple side-effects due to their lack of specificity, inherent toxicity and distribution in peripheral compartments. For instance, EDTA has been shown to be responsible for the excretion and depletion of essential metals like $\mathrm{Zn}$, $\mathrm{Cu}$, and $\mathrm{Mn}$, while BAL showed an increased deposit of metal in the brain [49]. This strongly supports the need to develop alternative strategies, especially through the use of polymeric binders, which enable the design and tuning of the physicochemical properties for the metal-binder complex.

Our group is currently developing a polymeric binder for in vivo biodetoxification of heavy metals, of which cadmium $\left(\mathrm{Cd}^{2+}\right)$ was selected as an illustrative model (Fig. 1A). Once absorbed, cadmium accumulates mainly in the liver, where it is sequestrated by metallothionein (MT), a low molecular weight protein dedicated to protect the cells from intracellular cadmium [50]. When the overload of cadmium exceeds the capacity of MT, damage to hepatocytes occurs and $\mathrm{Cd}^{2+}$ and cadmium-MT complexes are released in the blood. Renal toxicity comes from the receptor-mediated endocytic reabsorption and subsequent digestion of cadmium-MT complexes in the lysosomes of proximal tubule cells. Once the protein is destroyed, free $\mathrm{Cd}^{2+}$ causes major tissue damage and renal failure [51]. The strategy explored herein relies on the use of a functionalized 8-arm branched PEG which could bind cadmium in the blood circulation, decrease its tropism toward the liver, and ensure its renal elimination (Fig. 1A). A molecular weight of $20 \mathrm{kDa}$ was chosen to achieve a long circulation time (to maximize the chances of cadmium capture) while still allowing renal excretion [52]. The binding affinity was provided by terminal functionalization with theophylline units, which upon conjugation structurally resemble caffeine (Fig. 1B). Caffeine has been reported to bind cadmium through cationic-aromatic interactions [53].

The multi-branched PEG-caffeine conjugate (PEG-CAF) was produced by a two-step procedure (experimental schemes, procedures, and characterization of PEG-CAF are reported in the Supporting Information). The binding properties towards cadmium chloride $\left(\mathrm{CdCl}_{2}\right)$ were studied in vitro and in vivo. The interaction was first examined by FTIR spectroscopy. $\mathrm{CdCl}_{2}$ modified the FTIR spectra of caffeine and PEG-CAF in a similar manner (Figure S2). By spectrophotometry, it was found that both free caffeine and PEG-CAF exhibited the same binding affinity for $\mathrm{Cd}^{2+}\left(\mathrm{K}=3.68 \times 10^{5}\right.$ vs. $3.74 \times 10^{5} \mathrm{M}^{-1}$, respectively). The binding ability of caffeine moieties towards $\mathrm{CdCl}_{2}$ was indeed not affected by its conjugation to PEG. Since serum cadmium has been found to be largely bound to albumin at its free reduced cysteine residue [50], the competitive binding of albumin was challenged in vitro against PEG-CAF, and an equivalent concentration of free caffeine (Fig. 1C). PEG-CAF was able to displace cadmium bound to albumin in a dose-dependent manner. Interestingly, this effect was greater for conjugated PEG-CAF than free caffeine. In vivo, PEG-CAF was characterized with a long circulation time after i.v. injection $\left(\mathrm{t}_{1 / 2}=14 \mathrm{~h}\right.$, Figure S3), in agreement with the reported pharmacokinetics of related hydrophilic polymers [52,54]. The polymer conjugate was well tolerated and excreted in urine (Fig. 1D) with limited accumulation in the liver after $24 \mathrm{~h}$ (Table S2). The conjugation of caffeine to the branched PEG abolished its hemodynamic effects, as shown by the stability of hemodynamic parameters after i.v. administration of PEG-CAF (Table S3). While the ability of this binder to reverse cadmium intoxication remains to be established in vivo, these preliminary experiments demonstrate that PEG-CAF was well tolerated, long circulating, and able to displace albumin bound-cadmium. This confirms the substantial promise of PEG-CAF as a detoxifying agent.

\section{Macromolecular binders for small molecules and oligomers}

In comparison to ions, for which shape remains consistent, smallmolecules and oligomers are structurally more complex and thus offer more possibilities for achieving tight and selective binding. More specifically, the three dimensional structure and size of the substrate as well as the relative disposition of hydrophobic, aromatic, and/or charged regions can be exploited to achieve high selectivity and binding. Numerous cases of macromolecular binders for small molecules exist in the field of pharmaceutical sciences; some examples are listed in Table 1.

\subsection{State-of-the art}

For over 30 years, synthetic hosts have been designed to exploit both the facial amphiphilicity and the anionic tail of bile acids to achieve their sequestration from the GI tract. Bile acids are endogenous cholesterol-derived molecules responsible for the GI dispersion/solubilization of fatty acids and lipids. Sequestrants for bile acids block their entero-hepatic circulation and lower the concentration of cholesterol in the blood. Because they are non-absorbed, these compounds are generally regarded as safe and not associated with serious adverse effects. Colestipol (Colestid $®$ ) and cholestyramine (Questran ${ }^{\circledR}$ ) are first and second-generation compounds, respectively, consisting of cationic ion-exchanging resins capable of binding ionic bile acids through electrostatic interactions. The bile acid/resin complex is eliminated in the feces. More recently, new resins with added hydrophobic groups have been tailored to circumvent the low retention and binding capacity of the older resins. Colesevelam (Welchol ${ }^{\circledR}$ or Cholestagel $\AA$ ) and colestimide (Cholebine ${ }^{\circledR}$ ) exploit an optimized balance between hydrophilicity (capacity) along with hydrophobicity and tuned density of cationic groups (reduced desorption), in order to increase bile acid sequestration [44]. Other metabolic advantages on glycaemia have recently led to the approval of the colesevelam for the treatment of type II diabetes [55]. However, the mechanism behind this effect has not yet been elucidated [56].

Besides polymers, non-immunogenic cyclic oligosaccharides such as $\mathrm{CD}$ can be used as sequestrants and thus reverse the pharmacological effect of drugs. Sugammadex (Bridion ${ }^{\circledR}$ ) is an example of a $\gamma C D$ modified with an extended lipophilic core and a hydrophilic anionic periphery [57]. These two modifications were designed to accommodate the size of the hydrophobic guest and to interact with the positive charge of the drug's quaternary ammonium group. Consequently, this compound forms an exceptionally stable 1:1 complex with the neuromuscular blocking agent rocuronium $\left(\mathrm{K} \sim 10^{7} \mathrm{M}^{-1}\right)$ resulting from the co-operative abovementioned interactions [57,58]. During the optimization process, the influence of both the size of the hydrophobic cavity and the nature of the perfacial 2-O-substituents was assessed $[22,57]$. Various CD showed affinity for the drug. However, the most important structural features to ensure optimal activity were first, the 


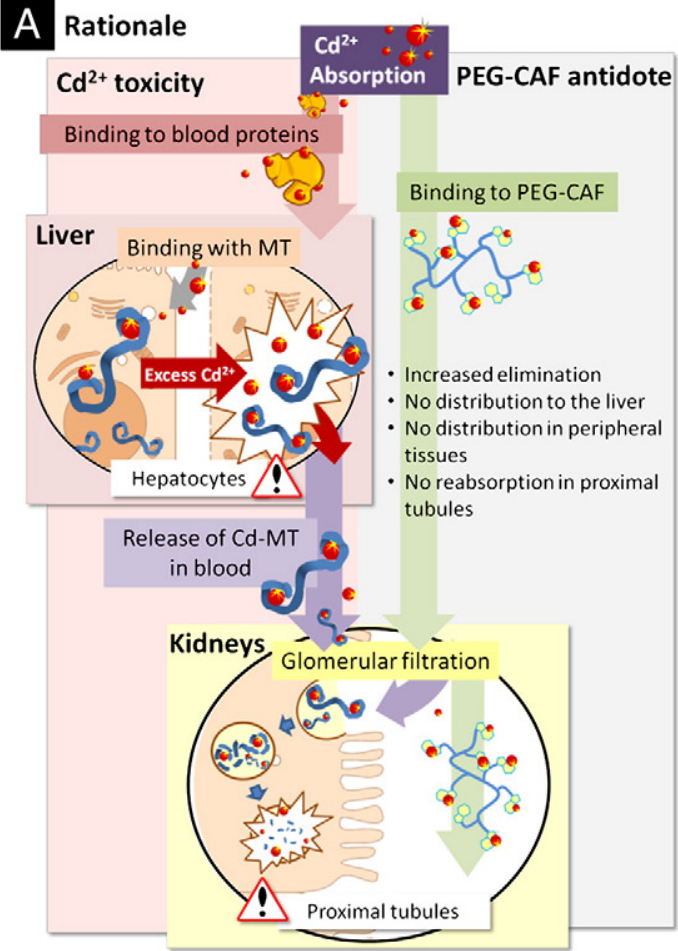

\section{B Structure of PEG-CAF}

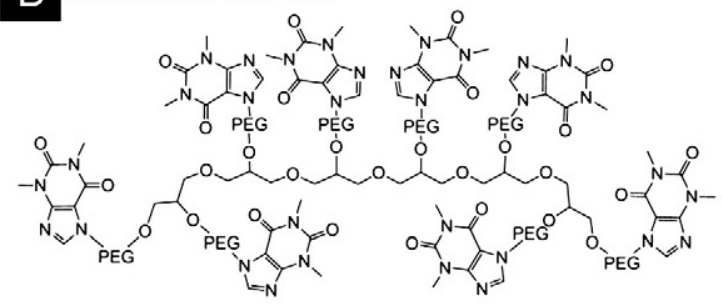

C PEG-CAF competes with albumin for $\mathrm{Cd}^{2+}$ binding

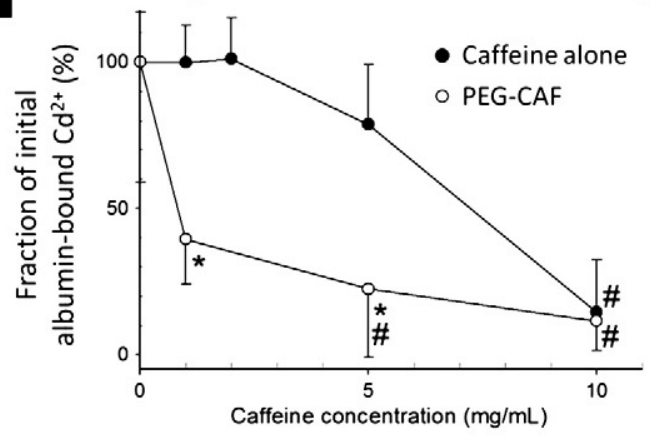

D PEG-CAF is eliminated through urine and feces

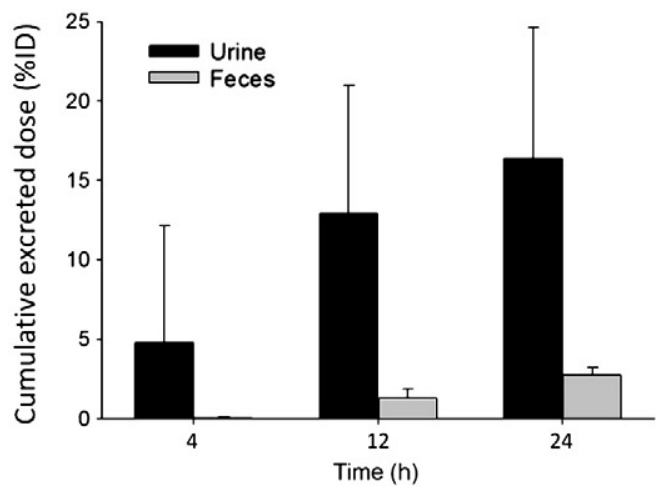

$\gamma C D$-structure possessing an hydrophobic cylindrical cavity slightly larger than the drug molecule ( 8 and $\sim 11 \AA$ of diameter and depth, respectively) and secondly, the presence of properly positioned negatively-charged groups [57]. After intravenous administration of the $\gamma C D$, the sequestration of the drug in the blood reduced its availability to bind the pharmacological target at the neuromuscular junction. The binding of rocuronium and other paralyzing agents to the inside cavity of sugammadex was shown to efficiently reverse the neuromuscular blockade of the drug in animals [59] and humans $[60,61]$. As opposed to pharmacological inhibitors that can cause various respiratory and cardiovascular adverse effects, sugammadex is verywell tolerated. For instance, its metabolism is negligible and more than $90 \%$ of the administered dose is excreted in the urine over $24 \mathrm{~h}[58,60]$. Several clinical studies have established the efficacy of sugammadex in reversing the neuromuscular blockade without inducing serious adverse events [62] and the macromolecular binder is approved for human use in the European Union. Sugammadex has some affinity to various other aminosteroid nondepolarizing muscle relaxants such as vecuronium (2.5-fold lower affinity), and pancuronium [63]. In addition to this example, other pharmacological applications of $\mathrm{CD}$ as binders are currently being studied. $C D$ are showing promise for altering the intracellular distribution of cholesterol in the treatment of certain genetic metabolic disorders $[21,64,65]$.

\subsection{Selected recent example: polycationic polymeric binders}

Aptamers are single-stranded nucleic acids that can bind and inhibit protein targets [66]. Sullenger et al. have developed customized aptamers forming stable complexes with coagulation factors (von Willebrand, factors VIIa and IXa) as anticoagulants used during surgical procedures $[67,68]$. In order to reverse the anticoagulant effect of the molecules and to limit perisurgical complications, subsequent efforts were put into the development of customized antidotes that could counter the effect of the nucleotides. The first proposed antidotes were oligonucleotide-based and were designed to form stable duplexes with the aptamers through Watson-Crick base pairing $[69,70]$. However the development of complementary strands for each aptamer proved cost-prohibitive and the formation of circulating double stranded RNA raised toxicity concerns [71]. In a recent study, polyvalent cationic macromolecular binders with affinity for nucleic acids were utilized to counteract the pharmacological activity of several aptamers in vitro and in vivo [23]. The rationale of this approach lies in the fact that systemically administered aptamers are the predominant extra-cellular oligonucleotides found in circulation and could thus be captured by the polymers in the blood (Fig. 2A). The authors observed that different anticoagulant aptamers could be inactivated by protamine, a small, arginine-rich, nuclear protein already known to bind DNA and heparin, but with substantial adverse effects. This prompted the screening of various polymers with intrinsic affinity for oligonucleotides to identify candidates with high binding efficiency. Several cationic polymers which have been traditionally used for nucleic acid delivery, including polyphosphoramidate polymers, $\beta$-cyclodextrin-containing polycations (CDP), and a third generation polyamidoamine dendrimer, were found to completely reverse the effects of these aptamers. In addition,

Fig. 1. Polymeric binder PEG-CAF for the treatment of cadmium intoxication. (A) Rationale behind the use of a polymeric binder to alleviate cadmium toxicity. PEG-CAF reduces the liver burden of cadmium, decreasing hepatotoxicity, and subsequent release of nephrotoxic cadmium-MT complexes, by binding $\mathrm{Cd}^{2+}$ in the blood and transporting it directly to the kidneys. (B) Structure of PEG-CAF. (C) Competitive assay between albumin and PEG-CAF for the binding of $\mathrm{CdCl}_{2}$. PEG-CAF is more efficient than free caffeine to displace $\mathrm{Cd}^{2+}$ from albumin. ${ }^{*} \mathrm{p}<0.05$ vs caffeine alone at the same concentration, ${ }^{\#} \mathrm{p}<0.05$ vs initial albumin-bound $\mathrm{Cd}^{2+}$ in the absence of caffeine (unpaired $t$-test). (D) Cumulative elimination of PEG-CAF in urine and feces over $24 \mathrm{~h}$ after i.v. administration. \%ID represents the percentage of injected dose. Mean \pm SD $(n=6)$ (Bertrand et al., unpublished data, see Supporting Information for details). 


\section{A Coagulation cascade}

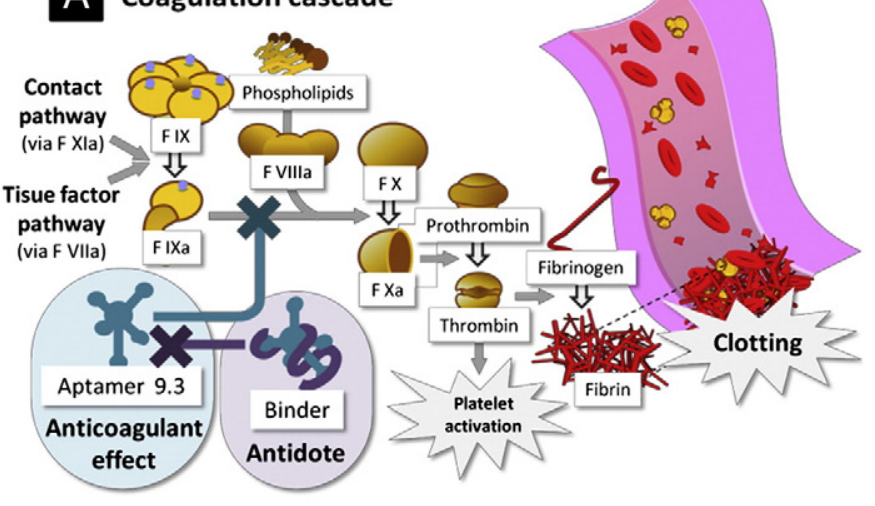

B

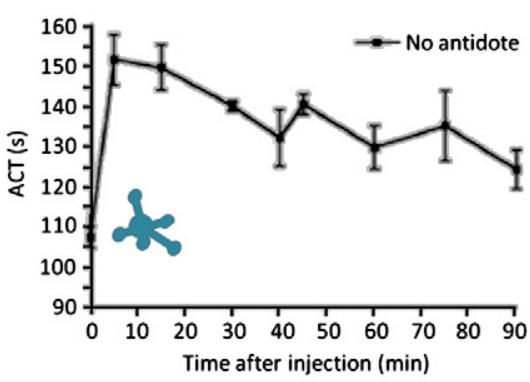

C

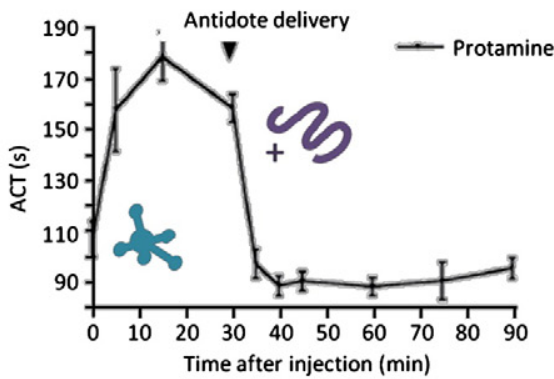

D

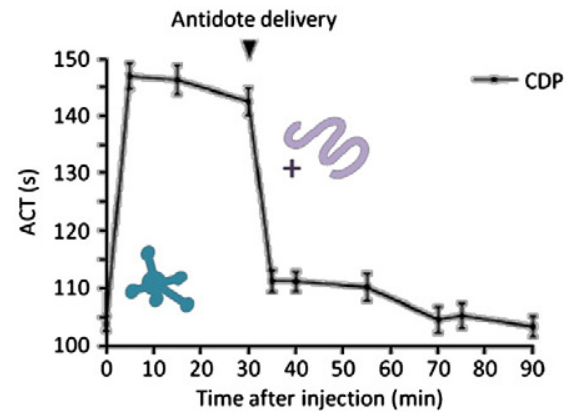

Fig. 2. Polymeric binders as antidotes against the anticoagulant effect of a factor IXa (F IXa)-targeted aptamer. (A) The inhibition of the coagulation cascade by the aptamer is tempered by a polymeric binder which prevents the nucleic acid molecule to reach its target. (B-D) In vivo active clotting times (ACT) of blood from swine treated with the $\mathrm{F}$ IXa aptamer 9.3t alone (B) or with the addition of protamine (C) or $\beta C D$-containing polycation (CDP) (D). The data are plotted as the means \pm s.e.m. for duplicate measurements from each pig $(n=5)$.

Panels (B), (C) and (D) are adapted with permission from reference [23].

their potency as antidotes correlated with their affinity for the RNA strands. Although no conclusions were drawn concerning the mechanisms of the interactions, binding strength and in vitro activity were correlated. Both the CDP and the polyphosphoramidates were able to neutralize various aptamers in whole blood, suggesting a sequence-independent interaction. In pigs, protamine and CDP rapidly ( $<5 \mathrm{~min}$ ) and durably ( $>60 \mathrm{~min}$ ) reversed the effects of an anticoagulant aptamer (Fig. 2B-D).

\section{Macromolecular binders for proteins}

Through multiple non-covalent co-operative interactions, macromolecular binders can sequester proteins with high avidity [72], and interfere with their mechanisms of action and/or promote their elimination. The affinity, selectivity, and activity of macromolecular binders strongly depend on the presence of specific recognition moieties (e.g., sugars), their density, and their three-dimensional presentation $[29,73,74]$. To date, the majority of the investigations involving the sequestration of proteins by polymeric binders have been conducted on bacterial toxins such as the Shiga [28,75], anthrax [30-32], and Clostridium difficile (C. difficile) toxins [76] (Table 1). The latter case is described in more detail in the following paragraph.

\subsection{State of the art}

C. difficile infection is a significant cause of nosocomial antibioticassociated diarrhea which is usually treated with metronidazole and vancomycin, antibiotics with activity against anaerobes. However, recent outbreaks and the emergence of hyper-virulent strains underscore the need for new therapeutics, which are ideally antibiotic-free. The pathogenesis is caused by two large secreted protein toxins, named toxins A and B. Both toxins bind to carbohydrates on the cell surface via a receptor-binding domain, and are subsequently endocyted. The toxin then translocates its enzymatic $N$-terminal domain to the cytoplasm where it disrupts essential cellular pathways. Several polymeric binders that target these toxins have been investigated. Cholestyramine was one of the first polymers proven to interact with $C$. difficile toxins [77]. This binder displayed some efficacy in case reports [78], but no definitive trial to date has supported its use. Furthermore, the polymer was found to bind with vancomycin [79], and therefore had to be dosed separately if used in combination with this antibiotic.

A recent effort in the design of a polymeric binder that inactivates the toxin has culminated with the clinical evaluation of tolevamer. Tolevamer is a high molecular weight poly(4-styrene sulfonate) (PSS) that was shown to bind toxin A and, to a lesser extent, toxin B via electrostatic and other non-covalent interactions $[72,80]$. The binding of tovelamer to $C$. difficile toxins was demonstrated to be not purely from electrostatic origin under physiological conditions [72]. In vitro experiments performed in phosphate buffers containing $0.15 \mathrm{M} \mathrm{Na}^{+}$ provided dissociation constants of $133 \mathrm{nM}$ and $8.7 \mu \mathrm{M}$ for the binding of tolevamer to toxins $A$ and $B$, respectively [72]. It was estimated that one polymer chain $(600 \mathrm{kDa})$ could bind a maximum of 3-4 toxin $A$ molecules. After oral intake, this high molecular weight polymer was excreted primarily in the feces and was therefore essentially not absorbed [81]. In a phase II clinical trial, sodium tolevamer showed promising results, especially for recurrent $C$. difficile infection [82]. It was later administered as mixed potassium-sodium salt instead of the pure sodium salt, to diminish the potential of hypokalemia by binding to intestinal potassium. Unfortunately, tolevamer ultimately failed in a phase III clinical trial in a non-inferiority test against metronidazole and vancomycin [25]. The compound had to be administered in high doses ( $9 \mathrm{~g} /$ day), presumably because of its low capacity and selectivity for the toxins.

A slightly more specific binder (synsorb 90) was produced by grafting the trisaccharide $\alpha \operatorname{Gal}(1-3) \beta G a l(1-4) \beta G l c$ on chromosorb P, a diatomite used in chromatography [73]. The exact nature of the human carbohydrate receptors interacting with the toxins is not known, but toxin A was found to bind to this trisaccharide [83]. At $200 \mathrm{mg} / \mathrm{kg}$ in mice, synsorb 90 offered protection against toxin A enterotoxicity, but at $400 \mathrm{mg} / \mathrm{kg}$, even chromosorb P showed activity, suggesting that the non-specific interactions were playing an important role as well [84]. Indeed, the development of synsorb 90 was abandoned in late clinical 
trials [25]. The fact that synsorb 90, like tolevamer, targeted mainly toxin A could have accounted for the suboptimal clinical activity given the recent understanding that toxin $\mathrm{B}$ is probably more important for pathogenesis $[85,86]$. Despite disappointing clinical outcomes, the impressive amount of data generated for $C$. difficile toxins binders has paved to way for the design of novel sequestrants for proteins.

\subsection{Selected recent example: poly(hydroxyethylmethacrylate-co-styrene sulfonate), $P$ (HEMA-co-SS)}

Celiac disease is an inflammatory condition of the small intestine triggered by the ingestion of gluten in genetically susceptible individuals. Screening studies have demonstrated that celiac disease is one of the most frequent genetically-based diseases with a worldwide prevalence of about 1\% [87]. Genetic predisposition is conferred by human leukocyte antigens (HLA): about $90 \%$ of affected people present HLA-DQ2 receptors and the remainder HLA-DQ8 [88]. Celiac disease is induced by immunogenic sequences of gluten proteins which are highly resistant to human digestive proteases. In the GI tract, a fraction of these peptides reaches the lamina propria, causing a T-cell mediated immune response (Fig. 3A). The current and only treatment is life-long elimination of gluten from the diet. This dietary restriction is a difficult experience for many patients and is often associated with a decreased quality of life. Poor compliance, whether inadvertent or voluntary, to a strict gluten-free diet is frequent and predisposes patients to celiac disease complications (e.g., nutritional deficiencies, osteoporosis, secondary autoimmune disorders, malignancies). Hence, there is an urgent need for complementary nondietary therapies to help treat this common disorder since it is associated with increased morbidity and mortality. Various therapeutic avenues are currently being explored to tackle this pathology [89]. These include administration of endopeptidases that can completely digest the immunotoxic gluten-derived peptides [90], modulators of intestinal permeability [91], inhibitors of tissue transglutaminases [92], HLA-DQ2 inhibitors [93], and vaccines [94].

Over the past few years, our group has been actively involved in the development of polymeric binders for gluten sequestration $[26,95]$. Notably, P(HEMA-co-SS) (ca. $50 \mathrm{kDa}$ ) has been shown to complex $\alpha$-gliadin (main immunogenic component of gluten) with fair selectivity in vitro compared to other food proteins such as albumin. Both HEMA and SS units were required to ensure effective sequestration at acidic and neutral pHs [96]. At acidic pH, SS monomers provided binding sites for hydrophobic (and/or $\pi-\pi$ interactions with aromatic amino acid residues) and electrostatic interactions. At $\mathrm{pH}$ 6.8, HEMA moieties promoted the formation of colloidal aggregates over a wide range of polymer concentrations, possibly through hydrogen bonding. The formation of these aggregates with $\mathrm{P}$ (HEMA-co-SS) is thought to limit the digestion and transmucosal absorption of gliadin (Fig. 3A). It was proven that the complexation of gliadin with the polymeric binder reduced the production of immunogenic peptides in the presence of GI enzymes [26]. In vitro, P(HEMA-co-SS) abolished the profound alterations in morphology and cell-cell contacts induced by gliadin on intestinal epithelial cells. In sensitized HLA-HCD4/DQ8 mice, a mouse model for gluten sensitivity, the co-administration of P(HEMA-Co-SS) attenuated gliadin-induced changes in intestinal permeability and inflammatory parameters (Fig. 3B and C) [26]. Moreover, rodents treated with the polymer did not exhibit side effects, even after massive and prolonged dosing. The binder's efficacy is now being further investigated under different preclinical settings, and ex vivo experiments using intestinal biopsies from celiac patients are currently underway.

\section{Macromolecular binders for viruses}

The docking of viruses on cells involves the coordination of a number of weak interactions [7]. Once bound to its target on the cell

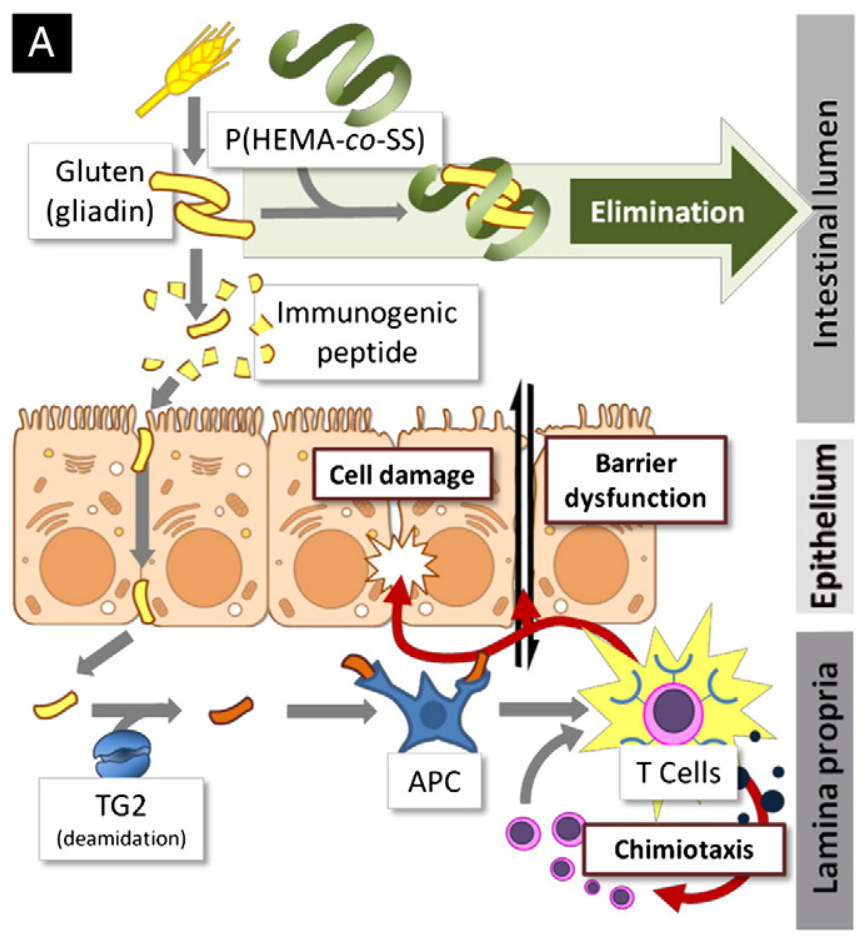

B
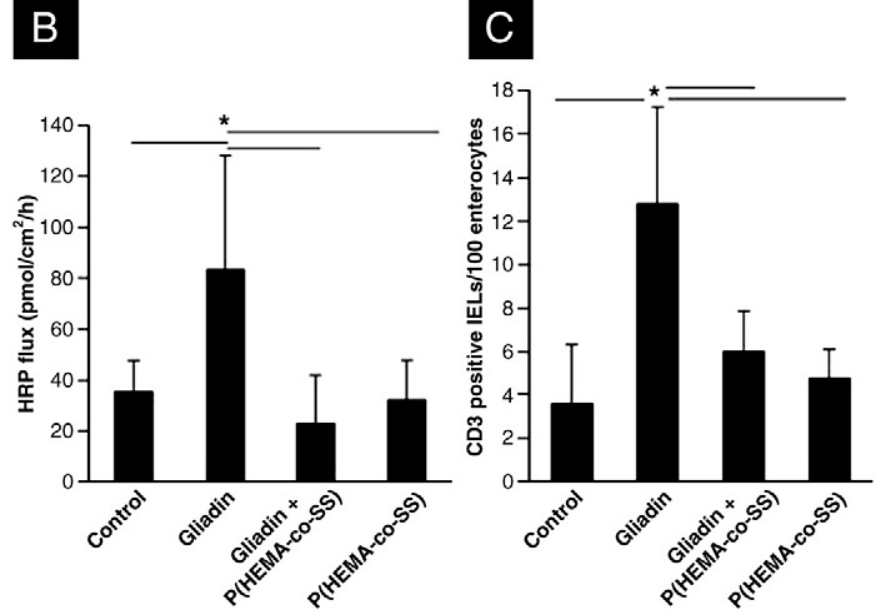

Fig. 3. Polymeric binders for the treatment of celiac disease. (A) The binding of $P$ (HEMA-Co-SS) to gliadin in the GI tract prevents the production of immunogenic peptides, reduces their permeability and inflammatory properties. TG2: tissue transglutaminase-2, APC: antigen-presenting cells. (B) P(HEMA-co-SS) abolished the gliadin-induced barrier dysfunction in vivo. (C) $\mathrm{CD}^{+}$intraepithelial lymphocytes in the lamina propria of HCD4/DQ8 mice. Controls consisted of non-sensitized mice gavaged with or without P(HEMA-Co-SS) $(6 \mathrm{mg})$. Treatment groups consisted of gliadinsensitized mice gavaged with whole gliadin $(2 \mathrm{mg})$ with or without polymer $(6 \mathrm{mg})$ ( $\mathrm{n}=6-7 /$ group). ${ }^{*} \mathrm{p}<0.05$.

Panels (B) and (C) are adapted with permission from reference [26].

surface, it then enters and replicates. Impeding interactions between viruses and cells decrease pathogen adhesion and internalization, and reduce virulence. Because of their multi-valency and high molecular weight, polymeric binders can act as potent antiviral compounds. Models have been proposed to prevent and treat influenza [35,36,97], herpes simplex virus (HSV) [98-100], and human immunodeficiency virus (HIV) infections [34,101,102]. Two different mechanisms explain the antiviral properties of the macromolecular binders (Fig. 4A): competitive inhibition of the virus-cell interactions and steric masking of the viral surface $[7,103]$. In the former process, the polymer targets a substrate deemed essential for cell docking. In the second mechanism, the formation of a flexible, shielding cloud around the virus makes it energetically unfavorable for the pathogen to 
A

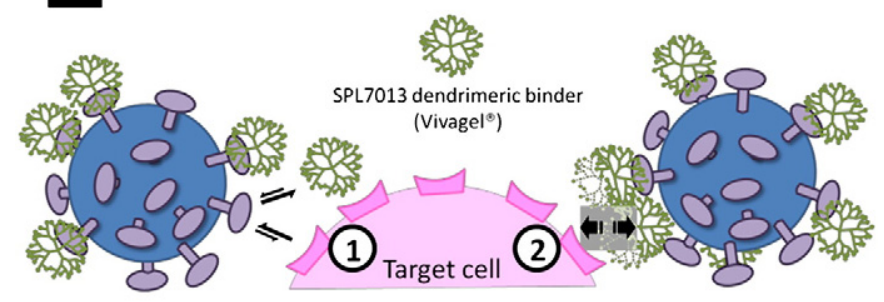

B

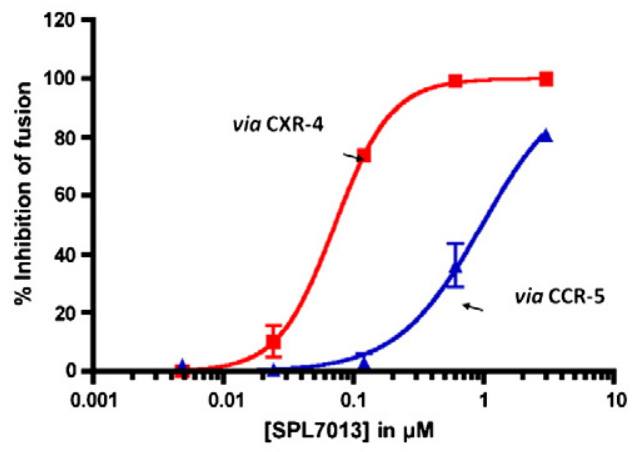

C

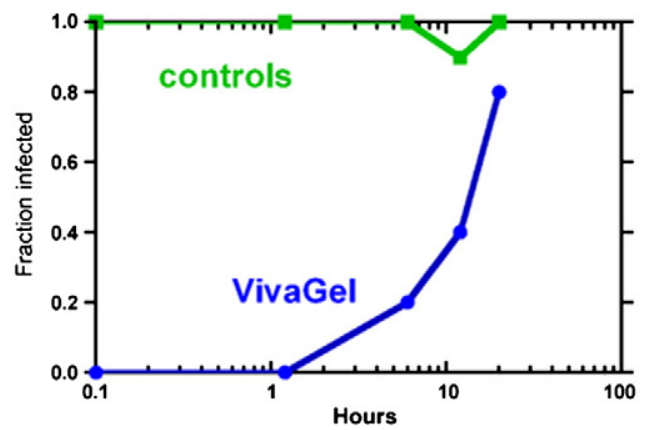

Fig. 4. The antiviral properties of a dendrimeric binder. (A) Schematic representation of the mechanisms behind the antiviral properties of SPL7013 and other macromolecular binders. 1) Competitive inhibition: by binding its substrate on the virus, the binder decreases the ability of the virus to anchor the cell surface. 2) Steric stabilization: the steric hindrance caused by the binding of the dendrimer to the virus inhibits the interaction with the cell surface. (B) In vitro inhibitory effect of SPL7013 in the fusion of HIV-1 strains with lymphocytes. The dose-dependent effect is visible on 2 strains of viruses targeting different cell receptors. Values represent means \pm s.e.m. for at least 3 independent assays. (C) In vivo evidence of the sustained antiviral protection conferred with a vaginal application of SPL7013 in mice. Groups of 10 mice received either a vaginal application of SPL7013 or phosphate buffer (control group) before a viral challenge of 10 times the $\mathrm{ID}_{50}$ (mean infected dose) of HSV-2.

Panels (B) and (C) are reproduced with permission from reference [34].

approach the cell. SPL7013 (VivaGel®), a poly(lysine)-based anionic dendrimer binder, is currently in clinical trials as a vaginal microbicide to prevent HSV and HIV infections [104]. The dendrimer (16 kDa, substituted with 32 naphthalene-3,6-disulfonate groups) was proven efficient in preventing HSV infection in mice and guinea pigs when applied vaginally before inoculation with the virus [34,99]. Likewise, the antiviral binder showed that it could prevent HIV infection in macaques [101]. Recently, a structure-activity study revealed that ionic and hydrophobic interactions with positively-charged components of the viral envelope of HSV-2 and HIV-1 inhibited the virus entry into the cell [34]. Inhibition of HIV-1 fusion with T lymphocytes was confirmed in both CXR-4 and CCR-5-targeting strains (Fig. 4B). Studies in mice proved that a vaginal application of a gel containing $3 \%$ SPL7013 conferred partial protection against HSV-2 up to $12 \mathrm{~h}$ after the microbicide application, and complete protection for $1 \mathrm{~h}$ (Fig. 4C) [34]. Clinical studies on the tolerability of a daily mucosal application of SPL7013-containing gel for 7 days have been completed $[105,106]$, and others on the efficiency in preventing HIV are at the planning stage.

\section{Macromolecular binders for bacteria}

The growing incidence of antibiotic-resistant bacterial strains is motivating the development of new antibacterial entities to treat infections. Since the discovery of naturally-occurring macromolecular antimicrobial peptides [107], strenuous efforts have been made to develop polymers with antibacterial properties. The most common approaches comprise membrane-disrupting polymers [108], antimicrobial drug-polymer conjugates [109], and polymeric binders $[38,39,110]$. The latter also offers interesting opportunities for biosensing and bacteria detection [111-113]. Different specific, external epitopes like sugars and proteins are anchored in the membrane of bacteria, and can be targeted by appropriately functionalized polymers [7]. In an elegant study, Whitesides et al. have designed a vancomycin/fluorescein-functionalized polyacrylamide polymer (pA-V-F) that could adsorb to Gram-positive bacteria and activate opsonisation of the pathogens to enhance phagocytosis (Fig. 5A) [38]. The multivalent vancomycin residues were used as binding moieties for D-alanine-D-alanine moieties (D-Ala-D-Ala) on the surface of the bacterial membrane. The fluorescein molecules were introduced to bind anti-fluorescein antibodies (IgGs). It was shown in vitro that the polymeric binder could fix various strains of bacteria through a vancomycin/D-Ala-D-Ala-dependent mechanism. The decoration of the bacteria with the polymer triggered fixation of anti-fluoresceinIgGs (Fig. 5B), and the opsonisation with IgGs enhanced phagocytosis of the bacteria by macrophages (Fig. 5C). The binder did not form stable complexes with Gram negative bacteria or vancomycinresistant bacterial strains for which the D-Ala-D-Ala residues were mutated to D-alanine-D-lactate. To the best of our knowledge, no in vivo studies have been performed to date to illustrate the efficacy of such an approach.

\section{Macromolecular binders for eukaryotic cells}

Cell surface receptors represent important targets for polymeric binders as they are involved in many signaling pathways and pathophysiological processes such as inflammation [40], immunity [114], and cancer [41]. Haag et al. have recently demonstrated that subcutaneously injected synthetic binders can be used to counteract inflammation [40]. They have shown that a dendritic polyglycerol sulfate could inhibit leukocytic L-selectin and endothelial P-selectin with high efficacy. Pharmacological inhibitors of selectin-mediated adhesion can indeed prevent the recruitment of circulating leukocytes to sites of inflammation and represent a promising strategy for the treatment of inflammatory disorders [115]. The polyglycerol sulfate hyperbranched polymer with an optimized spatial presentation of sulfate groups ( $6 \mathrm{kDa}$ core, 61 sulfate molecules) achieved multivalent electrostatic interactions with positively charged-protein motifs of Land P-selectins but also of the complement factors C3 and C5 (Fig. 6) [40]. In vivo, this polymeric binder succeeded in reducing leukocyte extravasation and œedema formation in a mouse model of contact dermatitis. In the field of oncology, polymeric binders also offer attractive perspectives. It was found that the coiled-coil mediated cross-linking of cell surface CD20 antigen through a synthetic $\mathrm{N}-(2$ hydroxypropyl)methacrylamide copolymer (PHPMA) backbone could trigger the apoptosis of tumoral cells in vitro [41].

\section{Conclusion}

In the present contribution, an illustration of the high potential of designing macromolecules with binding properties is given. It was shown that from small to larger substrates, selectivity can be improved by fine-tuning the structure of the binder and binding strengths 
A

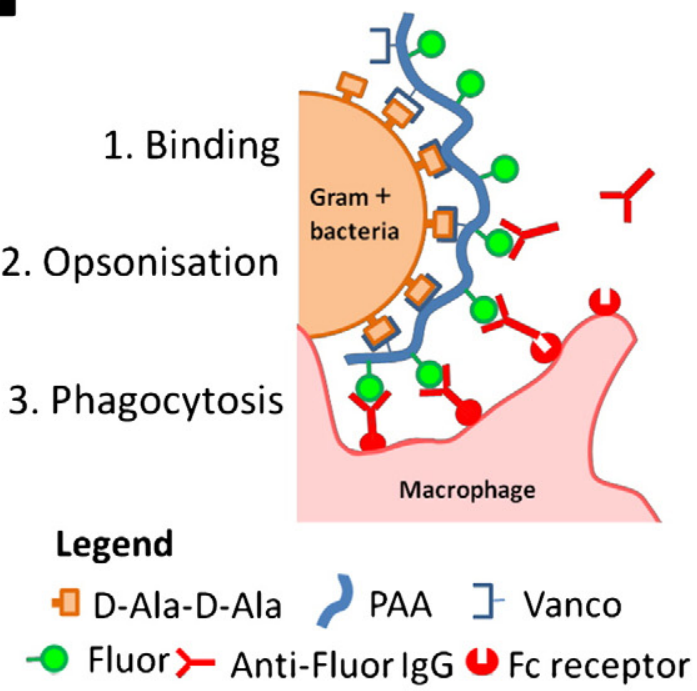

B
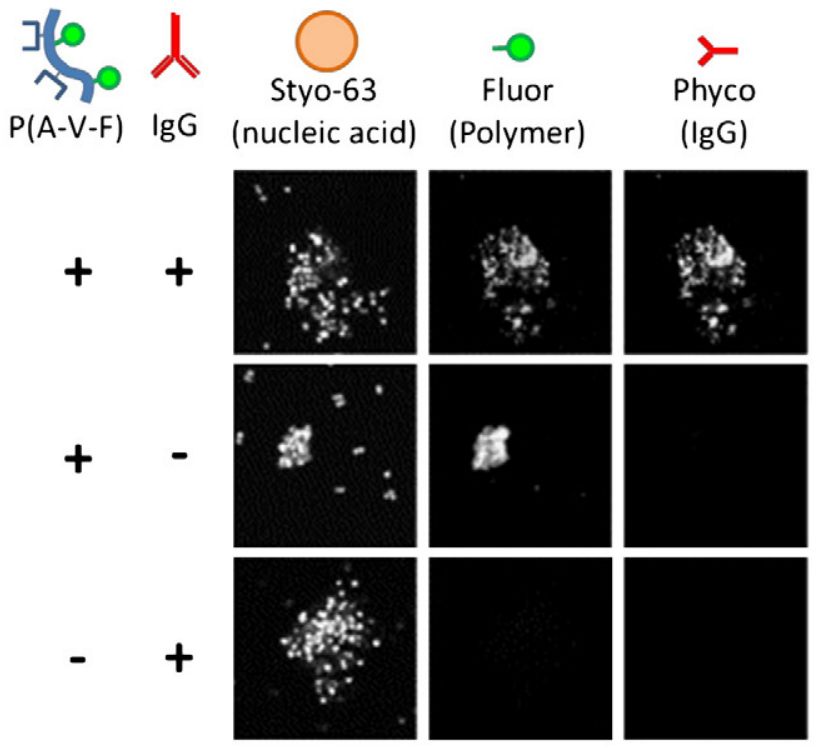

$\overline{10 \mu \mathrm{m}}$
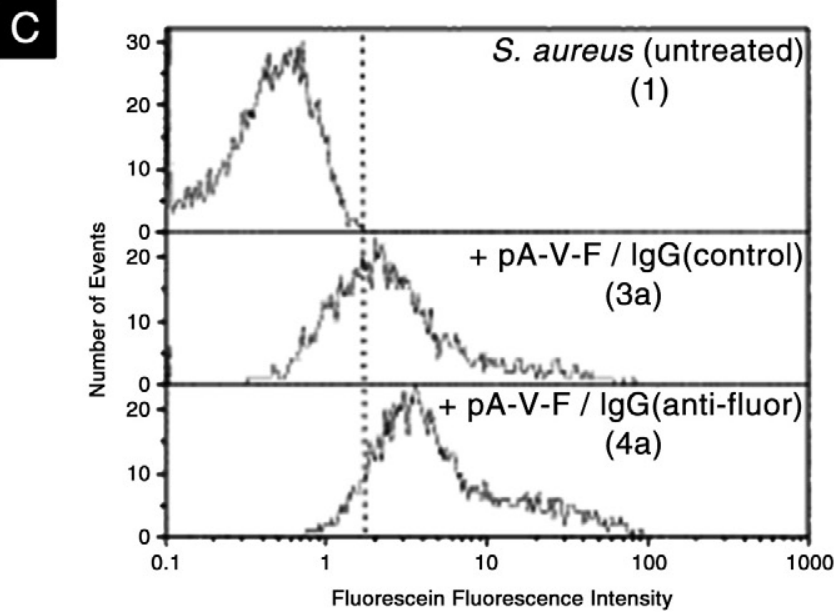

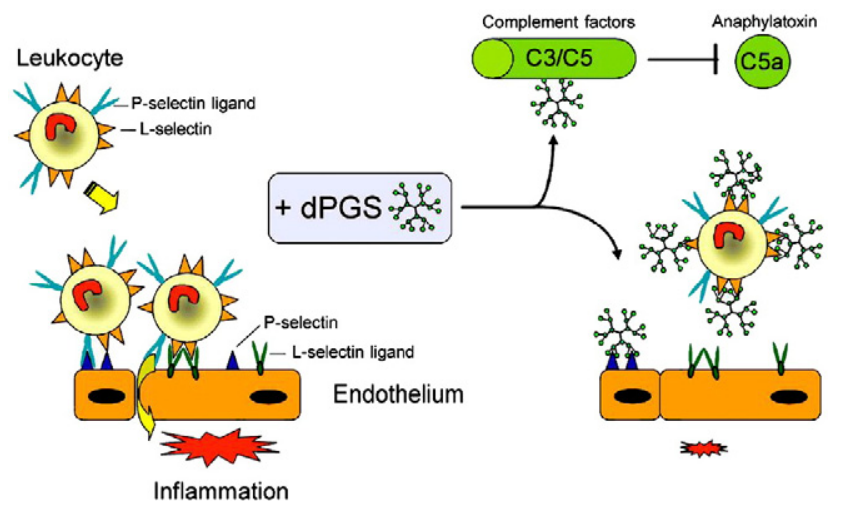

Fig. 6. Pleiotropic anti-inflammatory effect of dendritic polyglycerol sulfate (dPGS) diminishes the inflammatory response and reduces leukocyte extravasation. Molecular targets of dPGS are the adhesion molecules L- and P-selectin. dPGS prevents leukocyte extravasation by shielding the selectins. Binding to complement factors C3 and C5 inhibits the formation of the proinflammatory anaphylatoxins. Reduction of the C5a level decreases vascular permeability and further leukocyte extravasation. By addressing these inflammatory targets simultaneously, dPGS promotes the resolution of inflammation.

Reproduced with permission from reference [40].

comparable to those of biological receptors may be reached. Sequestration strategies applied to ions and small molecules are not new and have already been exploited with other types of colloidal systems [116,117]. However, the potential of macromolecular binders for larger substrates and their promise as future therapeutics have only recently been revealed. From heavy metal detoxification to the treatment of pathogen infections and celiac disease, a large variety of therapeutic applications are currently under clinical or pre-clinical development (Table 1). The pharmacological activity of such macromolecular binders relies on the efficacy and selectivity of binding to target substrates. Multiple complementary interactions (e.g., hydrophobic and electrostatic) are generally exploited to confer some selectivity. As opposed to molecularly imprinted polymers, where the binding moieties are supramolecularly organized within a three-dimensional matrix [14,15], the binders presented in this manuscript have a dynamic conformation in solution. The loss of selectivity that this difference imparts to polymeric binders can be compensated by higher accessibility of the binding moieties and accommodation of a wider range of substrate sizes compared to the molecular imprinting approach. These binders can thus be exploited in new therapeutic avenues, as shown by the recent examples for bacteria, viruses, and cells. These applications will explore multivalent specific recognition to "disguise" biological targets and exploit the cellular machinery and signaling pathways to trigger a therapeutic response. One should, of course, be aware that the use of macromolecular binders is not without drawbacks. The selection of pertinent biological targets will be paramount for designing successful binders. Obviously, the low diffusion rates of polymers across biological membranes may dictate the targeting of circulating, highly-accessible substrates. Likewise, although high-affinity and efficient binding can be reached, the high molecular weight of the compounds often translates into administration of large doses of binders. For example, sevelamer hydrochloride and cholestyramine must be administered daily in excess

Fig. 5. Polymeric binders for bacteria opsonisation. (A) Rationale of using a polymeric binder to promote opsonisation and phagocytosis on bacterium. The polymeric binder ( $\mathrm{pA}-\mathrm{V}-\mathrm{F}$ ) binds the D-Ala-D-Ala sequences of Gram positive bacteria through its vancomycin (Vanco) pendant groups and recruits anti-fluorescein IgGs thanks to its fluorescein units. (B) Fluorescence micrographs demonstrating binding of pA-V-F to $S$. Epidermidis and subsequent decoration with R-phycoerythrin-labeled anti-fluorescein IgGs. In control experiment, IgGs do not adhere to bacterias without pA-V-F. (C) Increase in macrophage fluorescence in the presence of $\mathrm{pA}-\mathrm{V}-\mathrm{F}$ and anti-fluorescein (anti-Fluor) IgG.

Panels (B) and (C) are reproduced with permission from reference [38]. 
of 3 and 20 g, respectively. To reduce the doses needed for a therapeutic impact, the binders will need to target highly potent signaling entities and cytokines or biological molecules which are keystones for selfamplified cascades. Finally, as of today, only limited toxicology data on macromolecules are available. Further knowledge in this field will be needed to ensure the clinical viability of the pharmaceutical applications using macromolecular binders [118].

\section{Acknowledgements}

This work was financially supported by the Natural Science and Engineering Research Council of Canada (Steacie fellowship to J.-C.L.) and the Canada Research Chair program. N.B. received a scholarship from Fonds de Recherche en Santé du Québec (FRSQ). Hui Gao, Raji AlKurdi, and François Plourde are acknowledged for their participation in either in vitro or in vivo experiments.

\section{Appendix A. Supplementary data}

Supplementary data to this article can be found online at doi:10.1016/j.jconrel.2011.04.027.

\section{References}

[1] R.A. Petros, J.M. DeSimone, Strategies in the design of nanoparticles for therapeutic applications, Nat. Rev. Drug Discov. 9 (2010) 615-627.

[2] D. Peer, J.M. Karp, S. Hong, O.C. Farokhzad, R. Margalit, R. Langer, Nanocarriers as an emerging platform for cancer therapy, Nat. Nanotechnol. 2 (2007) 751-760.

[3] R. Duncan, Polymer conjugates as anticancer nanomedicines, Nat. Rev. Cancer 6 (2006) 688-701.

[4] R. Duncan, The dawning era of polymer therapeutics, Nat. Rev. Drug Discov. 2 (2003) 347-360.

[5] K.L. Kiick, Polymer therapeutics, Science 317 (2007) 1182-1183.

[6] J. Rao, J. Lahiri, L. Isaacs, R.M. Weis, G.M. Whitesides, A trivalent system from Vancomycin-D-Ala-D-Ala with higher affinity than avidin-biotin, Science 280 (1998) 708-711.

[7] M. Mammen, S.-K. Choi, G.M. Whitesides, Polyvalent interactions in biological systems: implications for design and use of multivalent ligands and inhibitors, Angew. Chem. Int. Ed. Engl. 37 (1998) 2754-2794.

[8] F. van de Manakker, T. Vermonden, C.F. van Nostrum, W.E. Hennink, Cyclodextrin-based polymeric materials: synthesis, properties, and pharmaceutical/biomedical applications, Biomacromolecules 10 (2009) 3157-3175.

[9] J.W. Zhou, H. Ritter, Cyclodextrin functionalized polymers as drug delivery systems, Polym. Chem. 1 (2010) 1552-1559.

[10] J.E. Gestwicki, L.L. Kiessling, Inter-receptor communication through arrays of bacterial chemoreceptors, Nature 415 (2002) 81-82.

[11] X. Gong, D. Dubois, D. Miller, B. Shur, Activation of a G protein complex by aggregation of beta-1,4-galactosyltransferase on the surface of sperm, Science 269 (1995) 1718-1721.

[12] P.K. Dhal, S.C. Polomoscanik, L.Z. Avila, S.R. Holmes-Farley, R.J. Miller, Functional polymers as therapeutic agents: concept to market place, Adv. Drug Deliv. Rev. 61 (2009) 1121-1130.

[13] C.J. Hawker, K.L. Wooley, The convergence of synthetic organic and polymer chemistries, Science 309 (2005) 1200-1205.

[14] A. Bossi, F. Bonini, A.P.F. Turner, S.A. Piletsky, Molecularly imprinted polymers for the recognition of proteins: The state of the art, Biosens. Bioelectron. 22 (2007) 1131-1137.

[15] N.M. Bergmann, N.A. Peppas, Molecularly imprinted polymers with specific recognition for macromolecules and proteins, Prog. Polym. Sci. 33 (2008) 271-288

[16] M. Watson, K.C. Abbott, C.M. Yuan, Damned if you do, damned if you don't: potassium binding resins in hyperkalemia, Clin. J. Am. Soc. Nephrol. 5 (2010) $1723-1726$.

[17] P. Biggar, M. Ketteler, Sevelamer carbonate for the treatment of hyperphosphatemia in patients with kidney failure (CKD III-V), Expert Opin. Pharmacother. 11 (2010) 2739-2750.

[18] N.A.A. Rossi, I. Mustafa, J.K. Jackson, H.M. Burt, S.A. Horte, M.D. Scott, J.N Kizhakkedathu, In vitro chelating, cytotoxicity, and blood compatibility of degradable poly(ethylene glycol)-based macromolecular iron chelators, Biomaterials 30 (2009) 638-648.

[19] J. Lim, V.J. Venditto, E.E. Simanek, Synthesis and characterization of a triazine dendrimer that sequesters iron(III) using 12 desferrioxamine B groups, Bioorg. Med. Chem. 18 (2010) 5749-5753.

[20] T. Zhou, X.L. Kong, Z.D. Liu, D.Y. Liu, R.C. Hider, Synthesis and iron(III)-chelating properties of novel 3-hydroxypyridin-4-one hexadentate ligand-containing copolymers, Biomacromolecules 9 (2008) 1372-1380.

[21] L. Abi-Mosleh, R.E. Infante, A. Radhakrishnan, J.L. Goldstein, M.S. Brown, Cyclodextrin overcomes deficient lysosome-to-endoplasmic reticulum transport of cholesterol in Niemann-Pick type C cells, Proc. Natl. Acad. Sci. USA 106 (2009) 19316-19321.

[22] G.J. Tarver, S.J.A. Grove, K. Buchanan, A. Bom, A. Cooke, S.J. Rutherford, M.-Q Zhang, 2-O-substituted cyclodextrins as reversal agents for the neuromuscular blocker rocuronium bromide, Bioorg. Med. Chem. 10 (2002) 1819-1827.

[23] S. Oney, R.T.S. Lam, K.M. Bompiani, C.M. Blake, G. Quick, J.D. Heidel, J.Y.-C. Liu, B.C. Mack, M.E. Davis, K.W. Leong, B.A. Sullenger, Development of universal antidotes to control aptamer activity, Nat. Med. 15 (2009) 1224-1228.

[24] D.-W. Lee, J. Flint, T. Morey, D. Dennis, R. Partch, R. Baney, Aromatic-aromatic interaction of amitriptyline: implication of overdosed drug detoxification, J. Pharm. Sci. 94 (2005) 373-381.

[25] K. Weiss, Toxin-binding treatment for Clostridium difficile: a review including reports of studies with tolevamer, Int. J. Antimicrob. Agents 33 (2009) 4-7.

[26] M. Pinier, E.F. Verdu, M. Nasser-Eddine, C.S. David, A. Vézina, N. Rivard, J.C. Leroux, Polymeric binders suppress gliadin-induced toxicity in the intestinal epithelium, Gastroenterology 136 (2009) 288-298.

[27] G.L. Mulvey, P. Marcato, P.I. Kitov, J. Sadowska, D.R. Bundle, G.D. Armstrong, Assessment in mice of the therapeutic potential of tailored, multivalent shiga toxin carbohydrate ligands, J. Infect. Dis. 187 (2003) 640-649.

[28] M. Watanabe, K. Matsuoka, E. Kita, K. Igai, N. Higashi, A. Miyagawa, T. Watanabe, R. Yanoshita, Y. Samejima, D. Terunuma, Y. Natori, K. Nishikawa, Oral therapeutic agents with highly clustered globotriose for treatment of shiga toxigenic Escherichia coli infections, J. Infect. Dis. 189 (2004) 360-368.

[29] P.I. Kitov, G.L. Mulvey, T.P. Griener, T. Lipinski, D. Solomon, E. Paszkiewicz, J.M Jacobson, J.M. Sadowska, M. Suzuki, K.-i. Yamamura, G.D. Armstrong, D.R Bundle, In vivo supramolecular templating enhances the activity of multivalent ligands: a potential therapeutic against the Escherichia coli 0157 AB5 toxins, Proc. Natl. Acad. Sci. USA 105 (2008) 16837-16842.

[30] M. Mourez, R.S. Kane, J. Mogridge, S. Metallo, P. Deschatelets, B.R. Sellman, G.M. Whitesides, R.J. Collier, Designing a polyvalent inhibitor of anthrax toxin, Nat. Biotechnol. 19 (2001) 958-961.

[31] K.V. Gujraty, A. Joshi, A. Saraph, V. Poon, J. Mogridge, R.S. Kane, Synthesis of polyvalent inhibitors of controlled molecular weight: structure-activity relationship for inhibitors of anthrax toxin, Biomacromolecules 7 (2006) 2082-2085.

[32] A. Joshi, A. Saraph, V. Poon, J. Mogridge, R.S. Kane, Synthesis of potent inhibitors of anthrax toxin based on poly-L-glutamic acid, Bioconjug. Chem. 17 (2006) 1265-1269.

[33] B.F.L. Lai, Y. Zou, D.E. Brooks, J.N. Kizhakkedathu, The influence of poly-N-[(2,2 dimethyl-1,3-dioxolane)methyl lacrylamide on fibrin polymerization, crosslinking and clot structure, Biomaterials 31 (2010) 5749-5758.

[34] D. Tyssen, S.A. Henderson, A. Johnson, J. Sterjovski, K. Moore, J. La, M. Zanin, S Sonza, P. Karellas, M.P. Giannis, G. Krippner, S. Wesselingh, T. McCarthy, P.R Gorry, P.A. Ramsland, R. Cone, J.R. Paull, G.R. Lewis, G. Tachedjian, Structure activity relationship of dendrimer microbicides with dual action antivira activity, PLoS One 5 (2010) e12309.

[35] T. Honda, S. Yoshida, M. Arai, T. Masuda, M. Yamashita, Synthesis and antiinfluenza evaluation of polyvalent sialidase inhibitors bearing 4-guanidinoNeu5Ac2en derivatives, Bioorg. Med. Chem. Lett. 12 (2002) 1929-1932.

[36] A.S. Gambaryan, E.Y. Boravleva, T.Y. Matrosovich, M.N. Matrosovich, H.D. Klenk E.V. Moiseeva, A.B. Tuzikov, A.A. Chinarev, G.V. Pazynina, N.V. Bovin, Polymerbound $6^{\prime}$ sialyl-N-acetyllactosamine protects mice infected by influenza virus, Antiviral Res. 68 (2005) 116-123.

[37] US-NIH, Dose ranging study of SPL7013 gel for treatment of bacterial vaginosis (BV), http://clinicaltrials.gov/[Last accessed on: 2011-02-07].

[38] V.M. Krishnamurthy, L.J. Quinton, L.A. Estroff, S.J. Metallo, J.M. Isaacs, J.P Mizgerd, G.M. Whitesides, Promotion of opsonization by antibodies and phagocytosis of Gram-positive bacteria by a bifunctional polyacrylamide, Biomaterials 27 (2006) 3663-3674.

[39] J. Li, S. Zacharek, X. Chen, J. Wang, W. Zhang, A. Janczuk, P.G. Wang, Bacteria targeted by human natural antibodies using $\alpha$-Gal conjugated receptor-specific glycopolymers, Bioorg. Med. Chem. 7 (1999) 1549-1558.

[40] J. Dernedde, A. Rausch, M. Weinhart, S. Enders, R. Tauber, K. Licha, M. Schirner, U. Zügel, A. von Bonin, R. Haag, Dendritic polyglycerol sulfates as multivalent inhibitors of inflammation, Proc. Natl. Acad. Sci. USA 107 (2010) 19679-19684

[41] K. Wu, J. Liu, R.N. Johnson, J. Yang, J. Kopeček, Drug-free macromolecular therapeutics: induction of apoptosis by coiled-coil-mediated cross-linking of antigens on the cell surface, Angew. Chem. Int. Ed. Engl. 49 (2010) 1451-1455.

[42] H.-J. Schneider, Binding mechanisms in supramolecular complexes, Angew. Chem. Int. Ed. Engl. 48 (2009) 3924-3977.

[43] A. Bellasi, L. Kooienga, G.A. Block, Phosphate binders: new products and challenges, Hemodial. Int. 10 (2006) 225-234.

[44] P. Dhal, S. Holmes-Farley, C. Huval, T. Jozefiak, in: R. Satchi-Fainaro, R. Duncan (Eds.), Polymer Therapeutics I, vol. 192, Springer, Berlin / Heidelberg, 2006, pp. 9-58.

[45] ATSDR, CERCLA priority list of harzardous substances, http://www.atsdr.cdc gov/2007[Last accessed on: 2011-01-27].

[46] O. Barbier, G. Jacquillet, M. Tauc, M. Cougnon, P. Poujeol, Effect of heavy metals on, and handling by, the kidney, Nephron Physiol. 99 (2005) 105-110.

[47] W.C. Prozialeck, J.R. Edwards, D.W. Nebert, J.M. Woods, A. Barchowsky, W.D. Atchison, The vascular system as a target of metal toxicity, Toxicol. Sci. 102 (2008) 207-218.

[48] O. Andersen, Principles and recent developments in chelation treatment of meta intoxication, Chem. Rev. 99 (1999) 2683-2710.

[49] S.J.S. Flora, M. Mittal, A. Mehta, Heavy metal induced oxidative stress and its possible reversal by chelation therapy, Indian J. Med. Res. 128 (2008) 501-523. 
[50] G.F. Nordberg, Chelating agents and cadmium toxicity: problems and prospects, Environ. Health Perspect. 54 (1984) 213-218.

[51] A. Bernard, Cadmium and its adverse effects on human health, Indian J. Med. Res. 128 (2008) 557-564.

[52] T. Yamaoka, Distribution and tissue uptake of poly(ethylene glycol) with different molecular weights after intravenous administration to mice, J. Pharm. Sci. 83 (1994) 601-606.

[53] S. Nafisi, S.A. Sadjadi, S.S. Zadeh, M. Damerchelli, Interaction of metal ions with caffeine and theophylline: stability and structural features, J. Biomol. Struct. Dyn. 21 (2003) 289-296.

[54] N. Bertrand, J.G. Fleischer, K.M. Wasan, J.C. Leroux, Pharmacokinetics and biodistribution of $\mathrm{N}$-isopropylacrylamide copolymers for the design of $\mathrm{pH}-$ sensitive liposomes, Biomaterials 30 (2009) 2598-2605.

[55] K. Tziomalos, V.G. Athyros, D.P. Mikhailidis, Colesevelam improves glycemic control and lipid management in inadequately controlled type 2 diabetes mellitus, Nat. Clin. Pract. Endocrinol. Metab. 5 (2009) 16-17.

[56] B. Staels, A review of bile acid sequestrants: potential mechanism(s) for glucose-lowering effects in type 2 diabetes mellitus, Postgrad. Med. 121 (2009) 25-30.

[57] A. Bom, M. Bradley, K. Cameron, J.K. Clark, J. van Egmond, H. Feilden, E.J. MacLean, A.W. Muir, R. Palin, D.C. Rees, M.-Q. Zhang, A novel concept of reversing neuromuscular block: chemical encapsulation of rocuronium bromide by a cyclodextrin-based synthetic host, Angew. Chem. Int. Ed. Engl. 41 (2002) $265-270$.

[58] F. Gijsenbergh, S. Ramael, N. Houwing, T. van lersel, First human exposure of Org 25969, a novel agent to reverse the action of rocuronium bromide, Anesthesiology 103 (2005) 695-703.

[59] L. Booij, J. van Egmond, J. Driessen, H. de Boer, In vivo animal studies with sugammadex, Anaesthesia 64 (Suppl. 1) (2009) 38-44.

[60] I.F. Sorgenfrei, K. Norrild, P.B. Larsen, J. Stensballe, D. Ostengard, M.E. Prins, J. Viby-Morgensen, Reversal of rocuronium-induced neuromuscular block by the selective relaxant binding agent sugammadex, Anesthesiology 104 (2006) 667-674.

[61] M. Shields, M. Giovanelli, R. Mirakhur, I. Moppett, J. Adams, Y. Hermens, Org 25969 (sugammadex), a selective relaxant binding agent for antagonism of prolonged rocuronium-induced neuromuscular block, Br. J. Anaesth. 96 (2006) $36-43$.

[62] M. Naguib, Sugammadex: another milestone in clinical neuromuscular pharmacology, Anesth. Analg. 104 (2007) 575-581.

[63] A. Lenz, G. Hill, P.F. White, Emergency use of sugammadex after failure of standard reversal drugs, Anesth. Analg. 104 (2007) 585-586.

[64] B. Liu, S.D. Turley, D.K. Burns, A.M. Miller, J.J. Repa, J.M. Dietschy, Reversal of defective lysosomal transport in NPC disease ameliorates liver dysfunction and neurodegeneration in the npc1-/- mouse, Proc. Natl. Acad. Sci. USA 106 (2009) 2377-2382.

[65] A.I. Rosenbaum, G. Zhang, J.D. Warren, F.R. Maxfield, Endocytosis of $\beta$ cyclodextrins is responsible for cholesterol reduction in Niemann-Pick type C mutant cells, Proc. Natl. Acad. Sci. USA 107 (2010) 5477-5482.

[66] T. Hermann, D.J. Patel, Biochemistry - Adaptive recognition by nucleic acid aptamers, Science 287 (2000) 820-825.

[67] S. Oney, S.M. Nimjee, J. Layzer, N. Que-Gewirth, D. Ginsburg, R.C. Becker, G. Arepally, B.A. Sullenger, Antidote-controlled platelet inhibition targeting von Willebrand factor with aptamers, Oligonucleotides 17 (2007) 265-274.

[68] C.P. Rusconi, E. Scardino, J. Layzer, G.A. Pitoc, T.L. Ortel, D. Monroe, B.A. Sullenger, RNA aptamers as reversible antagonists of coagulation factor IXa, Nature 419 (2002) 90-94.

[69] C.K. Dyke, S.R. Steinhubl, N.S. Kleiman, R.O Cannon, LG. Aberle, M. Lin, S.K. Myles, C. Melloni, R.A. Harrington, J.H. Alexander, R.C. Becker, C.P. Rusconi, Firstin-human experience of an antidote-controlled anticoagulant using RNA aptamer technology: a phase 1a pharmacodynamic evaluation of a drugantidote pair for the controlled regulation of factor IXa activity, Circulation 114 (2006) 2490-2497.

[70] C.P. Rusconi, J.D. Roberts, G.A. Pitoc, S.M. Nimjee, R.R. White, G. Quick, E. Scardino, W.P. Fay, B.A. Sullenger, Antidote-mediated control of an anticoagulant aptamer in vivo, Nat. Biotechnol. 22 (2004) 1423-1428.

[71] M.E. Kleinman, K. Yamada, A. Takeda, V. Chandrasekaran, M. Nozaki, J.Z. Baffi, R.J.C Albuquerque, S. Yamasaki, M. Itaya, Y. Pan, B. Appukuttan, D. Gibbs, Z. Yang, K. Kariko, B.K. Ambati, T.A. Wilgus, L.A. DiPietro, E. Sakurai, K. Zhang, J.R. Smith, E.W. Taylor, J. Ambati, Sequence- and target-independent angiogenesis suppression by siRNA via TLR3, Nature 452 (2008) 591-597.

[72] W. Braunlin, Q. Xu, P. Hook, R. Fitzpatrick, J.D. Klinger, R. Burrier, C.B. Kurtz, Toxin binding of tolevamer, a polyanionic drug that protects against antibioticassociated diarrhea, Biophys. J. 87 (2004) 534-539.

[73] L.D. Heerze, M.A. Kelm, J.A. Talbot, G.D. Armstrong, Oligosaccharide sequences attached to an inert support (SYNSORB) as potential therapy for antibioticassociated diarrhea and pseudomembranous colitis, J. Infect. Dis. 169 (1994) 1291-1296.

[74] J.E. Gestwicki, C.W. Cairo, L.E. Strong, K.A. Oetjen, L.L. Kiessling, Influencing receptor-ligand binding mechanisms with multivalent ligand architecture, J. Am. Chem. Soc. 124 (2002) 14922-14933.

[75] P.I. Kitov, J.M. Sadowska, G. Mulvey, G.D. Armstrong, H. Ling, N.S. Pannu, R. Read, D.R. Bundle, Shiga-like toxins are neutralized by tailored multivalent carbohydrate ligands, Nature 403 (2000) 669-672.

[76] J. Peppe, A. Porzio, D.M. Davidson, A new formulation of tolevamer, a novel nonantibiotic polymer, is safe and well-tolerated in healthy volunteers: a randomized phase I trial, Br. J. Clin. Pharmacol. 66 (2008) 102-109.
[77] C. TeWen, B.O. Andrew, G.B. John, Anion-exchange resins in antibioticsassociated colitis, Lancet 312 (1978) 258-259.

[78] E.J. Burbige, F.D. Milligan, Pseudomembranous colitis, J. Am. Med. Assoc. 231 (1975) $1157-1158$

[79] N.S. Taylor, J.G. Bartlett, Binding of Clostridium difficile cytotoxin and vancomycin by anion-exchange resins, J. Infect. Dis. 141 (1980) 92-97.

[80] C.B. Kurtz, E.P. Cannon, A. Brezzani, M. Pitruzzello, C. Dinardo, E. Rinard, D.W.K. Acheson, R. Fitzpatrick, P. Kelly, K. Shackett, A.T. Papoulis, P.J. Goddard, R.H. Barker Jr., G.P. Palace, J.D. Klinger, GT160-246, a toxin binding polymer for treatment of Clostridium difficile colitis, Antimicrob. Agents Chemother. 45 (2001) 2340-2347.

[81] R.H. Barker Jr., R. Dagher, D.M. Davidson, J.K. Marquis, Tolevamer, a novel toxinbinding polymer : overview of preclinical pharmacology and physicochemical properties, Aliment. Pharmacol. Ther. 24 (2006) 10.

[82] T.J. Louie, J. Peppe, C.K. Watt, D. Johnson, R. Mohammed, G. Dow, K. Weiss, S. Simon, J.F. John, G. Garber, S.-C. Taber, D.M. Davidson, t.T.S.I. Group, Tolevamer, a novel nonantibiotic polymer, compared with vancomycin in the treatment of mild to moderately severe Clostridium difficile-associated diarrhea, Clin. Infect. Dis. 43 (2006) 411-420.

[83] K.D. Tucker, T.D. Wilkins, Toxin A of Clostridium difficile binds to the human carbohydrate antigens I, X, and Y, Infect. Immun. 59 (1991) 73-78.

[84] I. Castagliuolo, J.T. LaMont, B. Qiu, S.T. Nikulasson, C. Pothoulakis, A receptor decoy inhibits the enterotoxic effects of Clostridium difficile toxin A in rat ileum, Gastroenterology 111 (1996) 433-438.

85] S.A. Kuehne, S.T. Cartman, J.T. Heap, M.L. Kelly, A. Cockayne, N.P. Minton, The role of toxin A and toxin B in Clostridium difficile infection, Nature 467 (2010) 711-713.

[86] D. Lyras, J.R. O'Connor, P.M. Howarth, S.P. Sambol, G.P. Carter, T. Phumoonna, R. Poon, V. Adams, G. Vedantam, S. Johnson, D.N. Gerding, J.I. Rood, Toxin B is essential for virulence of Clostridium difficile, Nature 458 (2009) 1176-1179.

[87] G.J. Tack, W.H.M. Verbeek, M.W.J. Schreurs, C.J.J. Mulder, The spectrum of celiac disease: epidemiology, clinical aspects and treatment, Nat. Rev. Gastroenterol. Hepatol. 7 (2010) 204-213.

[88] L.M. Sollid, Coeliac disease: dissecting a complex inflammatory disorder, Nat. Rev. Immunol. 2 (2002) 647-655.

89] M. Pinier, G. Fuhrmann, E. Verdu, J-C. Leroux, Prevention measures and exploratory pharmacological treatments of celiac disease, Am. J. Gastroenterol. 105 (2010) 2551-2561.

[90] J. Gass, M.T. Bethune, M. Siegel, A. Spencer, C. Khosla, Combination enzyme therapy for gastric digestion of dietary gluten in patients with celiac sprue, Gastroenterology 133 (2007) 472-480.

[91] B.M. Paterson, K.M. Lammers, M.C. Arrieta, A. Fasano, J.B. Meddings, The safety, tolerance, pharmacokinetic and pharmacodynamic effects of single doses of AT1001 in coeliac disease subjects: a proof of concept study, Aliment. Pharmacol. Ther. 26 (2007) 757-766.

[92] R.E. Watts, M. Siegel, C. Khosla, Structure-activity relationship analysis of the selective inhibition of transglutaminase 2 by dihydroisoxazoles, J. Med. Chem. 49 (2006) 7493-7501.

[93] J. Xia, M. Siegel, E. Bergseng, L.M. Sollid, C. Khosla, Inhibition of HLA-DQ2mediated antigen presentation by analogues of a high affinity 33-residue peptide from alpha2-gliadin, J. Am. Chem. Soc. 128 (2006) 1859-1867.

[94] L.K. Catherine, D. James, C. Zhenjun, P.A. Robert, M. James, Immune tolerance induced by peptide immunotherapy in an HLA DQ2-dependent mouse model of gluten immunity, Gastroenterology 136 (2009) A-57.

[95] L. Liang, M. Pinier, J-C. Leroux, M. Subirade, Interaction of $\alpha$-gliadin with poly (HEMA-co-SS): structural characterization and biological implication, Biopolymers 91 (2009) 169-178.

[96] L. Liang, M. Pinier, J.-C. Leroux, M. Subirade, Interaction of $\alpha$-gliadin with polyanions: design considerations for sequestrants used in supportive treatment of celiac disease, Biopolymers 93 (2010) 418-428.

[97] S.-K. Choi, M. Mammen, G.M. Whitesides, Generation and in situ evaluation of libraries of poly(acrylic acid) presenting sialosides as side chains as polyvalent inhibitors of influenza-mediated hemagglutination, J. Am. Chem. Soc. 119 (1997) 4103-4111.

[98] E. Gong, B. Matthews, T. McCarthy, J. Chu, G. Holan, J. Raff, S. Sacks, Evaluation of dendrimer SPL7013, a lead microbicide candidate against herpes simplex viruses, Antiviral Res. 68 (2005) 139-146.

[99] D. Bernstein, L.R. Stanberry, S. Sacks, N. Ayisi, Y. Gong, J. Ireland, R. Mumper, G. Holan, B. Matthews, T. McCarthy, N. Bourne, Evaluation of unformulated and formulated dendrimer-based microbicide candidates in mouse and guinea pig models of genital herpes, Antimicrob. Agents Chemother. 47 (2003) 3784-3788.

[100] Y. Ohta, J.-B. Lee, K. Hayashi, T. Hayashi, Isolation of sulfated galactan from Codium fragile and its antiviral effect, Biol. Pharm. Bull. 32 (2009) 892-898.

[101] Y.-H. Jiang, P. Emau, J.S. Cairns, L. Flanary, W.R. Morton, T.D. McCarthy, C.-C. Tsai, SPL7013 gel as a topical microbicide for prevention of vaginal transmission of SHIV $89.6 \mathrm{P}$ in macaques, AIDS Res. Hum. Retroviruses 21 (2005) 207-213.

[102] J.I. Jay, B.E. Lai, D.G. Myszka, A. Mahalingam, K. Langheinrich, D.F. Katz, P.F. Kiser, Multivalent benzoboroxole functionalized polymers as gp120 glycan targeted microbicide entry inhibitors, Mol. Pharm. 7 (2009) 116-129.

[103] G.B. Sigal, M. Mammen, G. Dahmann, G.M. Whitesides, Polyacrylamides bearing pendant $\alpha$-sialoside groups strongly inhibit agglutination of erythrocytes by influenza virus: the strong inhibition reflects enhanced binding through cooperative polyvalent interactions, J. Am. Chem. Soc. 118 (1996) 3789-3800.

[104] R. Rupp, S.L. Rosenthal, L.R. Stanberry, VivaGel ${ }^{\mathrm{TM}}$ (SPL7013): A candidate dendrimer-microbicide for the prevention of HIV and HSV infection, Int. J. Med. 2 (2007) 561-566. 
[105] J. O'Loughlin, I.Y. Millwood, H.M. McDonald, C.F. Price, J.M. Kaldor, J.R.A. Paull, Safety, tolerability, and pharmacokinetics of SPL7013 gel (VivaGel ${ }^{\circ}$ ): a dose ranging, phase I study, Sex. Transm. Dis. 37 (2010) 100-104.

[106] M.Y. Chen, I.Y. Millwood, H. Wand, M. Poynten, M. Law, J.M. Kaldor, S. Wesselingh, C.F. Price, L.J. Clark, J.R.A. Paull, C.K. Fairley, A randomized controlled trial of the safety of candidate microbicide SPL7013 gel when applied to the penis, J. Acquir. Immune Defic. Syndr. 50 (2009) 375-380.

[107] M. Zasloff, Antimicrobial peptides of multicellular organisms, Nature 415 (2002) 389-395.

[108] M. Werthen, M. Davoudi, A. Sonesson, D. Nitsche, M. Mörgelin, K. Blom, A. Schmidtchen, Pseudomonas aeruginosa-induced infection and degradation of human wound fluid and skin proteins ex vivo are eradicated by a synthetic cationic polymer, J. Antimicrob. Chemother. 54 (2004) 772-779.

[109] J.H. Jeong, Y.S. Byoun, Y.S. Lee, Poly(styrene-alt-maleic anhydride)-4-aminophenol conjugate: synthesis and antibacterial activity, React. Funct. Polym. 50 (2002) 257-263.

[110] L. Qu, L. Gu, H. Li, S. Taylor, T. Elkin, P.G. Luo, T.-R.J. Tzeng, X. Jiang, R.A. Latour, F. Stutzenberger, A. Williams, Y.-P. Sun, Galactosylated polymeric nanoparticles: synthesis and adhesion interactions with Escherichia Coli, J. Biomed. Nanotechnol. 1 (2005) 61-67.
[111] M.D. Disney, J. Zheng, T.M. Swager, P.H. Seeberger, Detection of bacteria with carbohydrate-functionalized fluorescent polymers, J. Am. Chem. Soc. 126 (2004) 13343-13346.

[112] W. Yang, C.-Y. Pan, M.-D. Luo, H.-B. Zhang, Fluorescent mannose-functionalized hyperbranched poly(amido amine)s: synthesis and interaction with E. Coli, Biomacromolecules 11 (2010) 1840-1846.

[113] M.K. Müller, L. Brunsweld, A supramolecular polymer as a self-assembling polyvalent scaffold, Angew. Chem. Int. Ed. Engl. 48 (2009) 2921-2924.

[114] E.B. Puffer, J.K. Pontrello, J.J. Hollenbeck, J.A. Kink, L.L. Kiessling, Activating B cell signaling with defined multivalent ligands, ACS Chem. Biol. 2 (2007) 252-262.

[115] H. Ulbrich, E.E. Eriksson, L. Lindbom, Leukocyte and endothelial cell adhesion molecules as targets for therapeutic interventions in inflammatory disease, Trends Pharmacol. Sci. 24 (2003) 640-647.

[116] J.C. Leroux, Injectable nanocarriers for biodetoxification, Nat. Nanotechnol. 2 (2007) 679-684.

[117] N. Bertrand, C. Bouvet, P. Moreau, J.C. Leroux, Transmembrane pH-gradient liposomes to treat cardiovascular drug intoxication, ACS Nano 4 (2010) 7552-7558.

[118] R. Gaspar, R. Duncan, Polymeric carriers: preclinical safety and the regulatory implications for design and development of polymer therapeutics, Adv. Drug Deliv. Rev. 61 (2009) 1220-1231. 